\title{
An Empirical Research on Negative Transfer in College Non-English Majors' Chinese-English Sentence Translation
}

\author{
Hui Ni \\ Department of English, Heze University, Heze 274000, Shandong, China
}

\begin{abstract}
Nowadays, the transferred errors in non-English majors' Chinese-English(C-E) sentence translation, which have been ignored by many teachers, are very remarkable. It has deeply affected the total translation process and the accuracy of the translation version. Moreover, it also has affected the scores in all kinds of English tests for non-English majors. This paper is an empirical research which focuses on the negative transfer of college non-English majors in their C-E sentence translation. The research approach is the C-E translation test paper. The software Excel 2007 and SPSS 16.0 have been used to analyze. With respect to the results, the transferred errors in $\mathrm{C}$-E sentence translation, have taken up 73\%, especially in the field of syntax. The essential causes are found and some suggestions are given to College English Teaching based on the findings.
\end{abstract}

Index Terms-Chinese-English sentence translation, negative transfer, morphology, lexicon, syntax, transferred errors, implications

\section{INTRODUCTION}

Compared to English majors, the non-English majors in China don't have the atmosphere to facilitate their language input. Every week they only have four periods of lessons. Some of them usually put the textbook on the shelf until next lesson, not to mention the extracurricular reading. They have little chance to communicate with the foreign teachers and reluctant to open their mouth. Only a few students who have intrinsic motivation are interested in learning English. Some others are quite bored at English. And there're also a group of students learning English because they have to pass the exams, such as College English Test (CET) band-4\&6, so many of them lack learner autonomy. As for the teachers, some of them give the lessons just to finish the task of teaching. They don't try to stimulate the interests of the students. According to the new College English Syllabus, the purpose of college English Teaching is to develop the integrated English language competence of the students. They should acquire the oral and written communication skills which are essential for their future work and social communication. Considering the current situation of college English learning and teaching, it's still a long way to achieve this goal. Especially the general state of the freshmen and sophomores is not optimistic.

Most studies on language transfer conducted at home and abroad focus on definitions and theoretical justification of language transfer; the role of transfer in discourse, semantics, syntax, phonology and writing systems; the analysis of MT transfer in second language acquisition (SLA); the influence of MT to foreign language (FL)/second language (SL) learning; MT strategy and MT transfer in students' writing and the influence of MT to lexical acquisition (Ellis, 1985; Odlin, 2001). Negative transfer from mother tongue in C-E sentence translation is a common phenomenon in the English learning of Chinese college students. However, it has not been given adequate attention by prior researches.

\section{LITERATURE REVIEW}

\section{A. Theories about Language Transfer}

In language learning, "transfer" is defined by behaviorist psychologists to refer to the process of automatic, uncontrolled and subconscious use of past-learned behaviors in the attempt to produce new responses. Of course, past-learned knowledge can play two definitely different roles in the learning of new ones, and accordingly, transfer falls into two types, namely positive transfer and negative transfer. As the name suggests, positive transfer occurs when the learner's previous knowledge, skill or ability facilitates his learning of new ones, while negative transfer refers to the impediment the learned knowledge, skill, or ability exerts upon the new learning.

Transfer was considered responsible for error occurrences in cross-linguistic and cross-cultural studies (Lado, 1957; Corder, 1969). In language learning transfer refers to the effect of one language on the learning of another, as Lado points out: "individuals tend to transfer the forms and meanings and the distribution of forms and meaning of their native language and culture to the foreign language and culture" (p. 2).

\section{B. Error Analysis}


Error analysis (EA) concerns with the process of determining the incidence, nature, causes and consequences of unsuccessful language. EA provides a methodology for investigating learner's language.

An error is defined as a deviation from the norms of the target language. In his 1967 paper, Corder makes a distinction between a mistake and an error. A mistake is a random performance slip caused by fatigue, excitement and so on and can be readily self-corrected; an error is a systematic deviation made by learners who have not yet mastered the rules of the second language. A learner can not self-correct an error because it is a product reflection of his or her current stage of second language development or underlying competence.

Many researchers have been attempting to investigate the types of errors, Richards (1974) distinguishes errors as interlingual errors and intralingual errors.

Interlingual errors are caused by the interference of mother tongue, such errors occur as a result of the use of the elements from one language while speaking another. While intralingual errors result from the target language. EA aims at the thorough description of learner's linguistic system and comparing it with that of the target language by reconstructing the correct utterance of target language and matching the "erroneous utterance" with its equivalence in learner's native language.

Here, the theory of error analysis serves as a theoretical guidance to identify the linguistic errors in the students' translation products. It is very applicable to analyze production errors and is termed as Transfer Analysis (TA) by James (2001). Here is a paradigm cited from James.

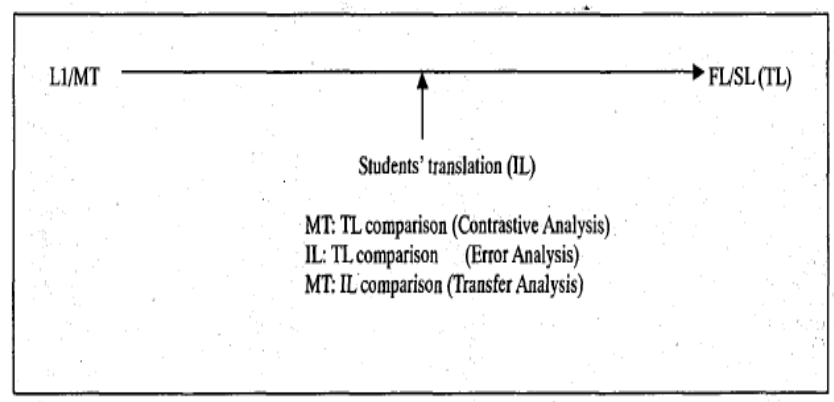

Points of comparison for successive FL learning paradigms:

\section{Translation and Contrastive Teaching}

Wolfram Wilss has did some research on the relation between contrastive linguistics and translation, he said, contrastive linguistics... is becoming more interested in the applicability of translation to foreign language pedagogy, on the one hand, contrastive linguistics is of growing importance for the science of translation, because structural divergences on syntactic, semantic, and stylistic levels produce textual equivalence problems which are the main object of TL (Target Language) (Wilss, 1996).

A contrastive study of Chinese and English not only helps to form a new method of language study that can be applied to translation, but also reveals the cognitive patterns respectively inherent in Chinese and English. In addition, contrastive linguistics may assist translators in gaining a better insight into peculiarities of the Chinese and the English languages, thus facilitating the translation process. On the one hand, an in-depth contrastive analysis of the Chinese and English sentence patterns can lead to a revelation of their similarities and dissimilarities; on the other hand, rational inferences or conclusions might result due to prudent contrastive analysis. Every language has its own system. As to translation studies, an understanding of the homogeneity and heterogeneity of the source language and the target language is of great importance.

\section{Comparison between English and Chinese at Sentence Level}

It is now universally accepted that the sentence is the key linguistic unit to realize communication and any language has its finite rules to build infinite sentences. A comparative study of English and Chinese has been made in the building of basic and commonly used sentence patterns. The study shows the two languages have not much in common in this field. The English sentence centers around the verb and so the basic sentence patterns are formed according to the structure of the Verb Phrase ( $\mathrm{Vph})$, and it may be formulated as below:

$\mathrm{S}($ Sentence $)=\mathrm{Nph}($ Noun Phrase $)+$ Vph (Verb Phrase) .

In contrast, the Chinese sentence does not necessarily depend on the verb and the basic sentence patterns are formed on the basis of amalgamation of words. Some of the modern Chinese grammarians hold that a Chinese sentence is based on two parts: THEME and RHEME. In terms of "theme" they mean the topic; and in terms of "rheme" they mean the comment. So comes the general formula:

$\mathrm{S}=\mathrm{T}($ heme $)+\mathrm{R}$ (heme)

Therefore, it is more convenient for us to analyze the Chinese sentence structure according to the structure within the two parts. On the basis of this analysis come two groups of sentence patterns: the T(heme)-type sentence pattern and the $\mathrm{R}$ (heme)-type sentence patterns. 
So English and Chinese are two quite different languages. The structure of Chinese is not as close with that of English as other European languages. Therefore, it is quite easy for Chinese students, esp. non-English majors, to create Chinglish when they translate Chinese into English if they are not aware of those differences. Many scholars have been doing research on the differences between Chinese and English. For example, Lian Shuneng has made a detailed comparison of Chinese and English in his Contrastive Studies of English and Chinese. He points out 10 major differences between Chinese and English at the sentence level. For example, English is compact, while Chinese is diffusive, English hypotactic, Chinese paratactic, and English uses more passive voice than Chinese, etc.

\section{EMPIRICAL RESEARCH}

\section{A. Research Design}

Research objects:

The study is designed to investigate negative transfer in C-E sentence translation. The experimental research in this part is to address the following questions:

(1) What are the main transfer errors occurred in the students C-E sentence translation version, and what are their frequencies?

(2) What are the causes of these kind of errors and are there any solutions?

(3) Are there any correlations between the number of transferred errors and the students English levels?

Research subjects:

Two parallel classes in the Economy Department in Heze University have been chosen as the experiment subjects. There're 50 students in each class, their scores in College Entrance Examination are similar. A test paper of C-E translation was distributed to them. Their translations have been collected, examined and analyzed. The translation paper consists of 30 sentence translations from Chinese to English, during which No.1-10 are from the New Horizon College English (book 1), No.11-20 are from the translation materials of CET-3, and No. 21- 30 are from the website of China Cyber Learning. The test paper can be seen in the appendix. In this chapter all the examples and data come form the students' translation version.

\section{B. A General View of the Students'Translation Versions}

The test papers were finished in one period and all of them have been taken up. Of all the 100 test papers, 30 samples which have been chosen randomly are put into careful study and analysis. The total error number is 313 , in which the transferred error is 228 and non-transferred error is 85. All the transferred errors can be classified in morphology, lexicon and syntax. The error types and frequencies in the translation versions of these 30 students have been listed in the following table:

TABLE 3-1

ERROR TYPES AND FREQUENCIES IN STUDENTS' TRANSLATION VERSION

\begin{tabular}{|l|l|l|}
\hline Type & Number of errors & Percentage \\
\hline article & 4 & $1 \%$ \\
\hline case & 3 & $1 \%$ \\
\hline number & 3 & $1 \%$ \\
\hline tense & 9 & $3 \%$ \\
\hline (adj. /adv.)comparison & 4 & $1 \%$ \\
\hline derivatives & 9 & $3 \%$ \\
\hline Choice of words and collocations & 22 & $7 \%$ \\
\hline omission of "be" and particles & 11 & $4 \%$ \\
\hline agreements & 24 & $8 \%$ \\
\hline word order & 19 & $6 \%$ \\
\hline relative clause & 17 & $5 \%$ \\
\hline negation & 13 & $4 \%$ \\
\hline dangling modifier & 11 & $4 \%$ \\
\hline "It" plague & 7 & $2 \%$ \\
\hline missing subject & 8 & $3 \%$ \\
\hline misplaced emphasis & 9 & $3 \%$ \\
\hline run-on sentence & 13 & $4 \%$ \\
\hline avoidance of passive voice & 16 & $5 \%$ \\
\hline avoidance of complex sentences & 14 & $4 \%$ \\
\hline the use of punctuations & 12 & $4 \%$ \\
\hline total number & 228 & $73 \%$ \\
\hline non-transferred errors & 85 & $27 \%$ \\
\hline
\end{tabular}

Notes: The above classification of transferred errors is based on the theory of Terence Odlin (2001) and Professor Yu Liming (2004).

From the above table, we can see that the transferred errors are very predominant, which is as high as $73 \%$ of the total errors. In the following part, there's a detailed analysis of these errors in three major categories. 
1. The transferred errors in morphology

One of the predominant features of Chinese is that it's an isolated language, which doesn't have any grammatical morphemes. Compared with Chinese, English has much more variations in morphology and therefore has more grammatical morphemes. So students have created some errors in this aspect.

a. Articles

There is no counterpart in Chinese for the articles, namely a, an and the, and that is why Chinese students are unable to find an equivalence in Chinese so as to better understand and use these articles in English acquisition.

E.g., she is excited by a idea of online learning..... (Sentence 2)

The people are increasingly having access to...... (Sentence 4)

...... I heard (the) clock strike 12:00. (Sentence 7)

b. Case

Case is a grammatical category of noun or pronoun that indicates the relations between them and other words of a sentence. The three cases in English are nominative case, objective case and possessive case.

Generating an action, the noun or pronoun is nominative case; being the receiver or the object of the action, it is objective case; referring to the person or thing that indicates the owner or possessor of something, it is possessive case. In English, the form of a noun which indicates subjective case or objective case will not change, because the word order in the sentence will specify its relations with other words. But when a noun indicates possessive case, the form of it will change. In contrast, there is no such case or morpheme indicating its relations with other words as subject, direct object or indirect object and other grammatical relations in Chinese. In addition, when a noun in Chinese indicates possessive case, it does not inflect as in English. Due to the differences between the two languages, errors are unavoidable in the use of case for Chinese students. E.g.,

I don't know whether him would come or not. (Sentence 10)

......, and this made she relax a little. (Sentence 11)

c. Number

In English, the concept of number is greatly different from that in Chinese. The nouns in English can be divided into countable nouns and uncountable nouns. The countable nouns such as "book" have plural forms while the uncountable nouns such as "faith" generally have no plural form. There are also some mass nouns and abstract nouns such as "rain" and "difficulty" which have plural forms expressing special meanings. In general, the singular form of a countable noun plus "s" or "es" arrives at its plural from such as "table - tables", "box-boxes" with the exception of irregular nouns such as "crisis - crises", "sheep - sheep", etc. But the plural forms in Chinese shares the following features: (1) can not be used with numerals; (2)refer to a group as a whole; (3) “们” "and “些” can be added to some pronouns or adjectives to express plural meanings, such as “我们”, “孩子们”, “人们”, “这些”, “那些”, “一些”, “好些”, etc. Owing to such great differences, some English learners are subject to several errors in this aspect. E.g.,

Communicating with native English speaker(s) is a worthy experience ...... (Sentence 3).

Some people think that boy(s) is (are) cleverer than girl(s). (Sentence 23)

d. Tense

The tenses between English and Chinese have great differences in that English verbs undergo inflectional changes such as the present tense of verbs, the third-person singular forms of verbs, the past tense of verbs, the past participle of verbs, the voices of verbs, the gerund and infinitive forms, etc, while Chinese verbs do not. Chinese verbs are never changed in any tense, but usually the combination of the adverbs of time such as “昨天”, “那天”, “现在”, “明天”, etc, with some other words as “过”, “了” “正”, “正在”, “会”, “将”, “要”, “就”, “着”, etc, are used to express the changes of tenses. Owing to such great difference between English and Chinese, some students always make various errors in tense. E.g.,

A teaching meeting is (will be) held in the school hall at 2:00 p.m. tomorrow. (Sentence 10)

......, a big progress (has been) is made in graduate education in China. (Sentence 25)

e. Comparative degrees

There is no grammatical category of comparative degree and superlative degree for adjective in Chinese, instead, the comparative meaning can be conveyed by using the Chinese characters such as “比”, “较”, “于”, “更”, “最”, “次于”, etc. But in English the form of an adjective will be changed, such as adding "er", or "est" to its positive form, or using "more", "most", "less", "least" as modifiers. There are also some irregular adjectives beyond these rules. The obvious difference contributes to a series of errors in the students' translations. E.g.,

Some people believe that boys are more clever (cleverer) than girls...... (Sentence 23).

f. Derivatives

Derivative is an important way of word building in English. A new word can be formed by add a prefix or suffix. The meaning of the root can be changed when added with an affix. E.g. the noun "kindness" can be formed if we add the suffix "ness" to the root adjective "kind". However, in Chinese, it's a different case. A Chinese word may have different meaning in different context, but the form doesn't change at all. i.e., the Chinese word can work as a verb as well as a noun in the same form. Due to this difference, students are easy to commit some mistakes in this aspect. E.g.,

, while he considers it not meaningful (meaningless) and useful. (useless). (Sentence 2).

Modest (Modesty) makes people make progress, ......(Sentence 20). 
2. The transferred errors in lexicon

The transferred errors in lexicon also account for a large percent in C-E translation. One can not go without adequate mental lexicon as storage when writing. With the limitation of mental lexicon, some students feel confused especially when they undergo difficulty in finding the corresponding words in English, and they are liable to bridge the gap by the native language, which is inevitable to result in negative transfer of native language. The remarkable manifestation is mechanical translation from Chinese. E.g.,

Calmly and patiently dealing with this question is wise. (Sentence 8)

Even though we failed a hundred times, the heaven will not collapse..... (Sentence 24).

In the above two examples, the italicized words are typical transferred vocabulary from Chinese. While the reference translations are:

It would be wise to handle this delicate problem with calmness and patience.

The world won't end even if we fail a hundred times.

3. The transferred errors in syntax

a. The omission of the verb "Be" and particles

The omission of the linker verb "Be" is due to the fact that in Chinese there's no such kind of verb. We can consider the verb “是” as a linker verb in Chinese, but it's usually not correspondent with that in English. Further more, there are many phrase verbs in English, i.e. a particle is usually added to a verb to fulfill a complete meaning. However, in Chinese, a verb is not necessarily followed by such a particle. Due to this difference, the omission of "Be" and particles is a frequent phenomenon in the students' versions. E.g.,

I feel that the sweeping cars (are) very merciless, ...... (Sentence 14)

...... and invite him (to) our English evening. (Sentence 27)

b. Agreement

In English, agreement refers to accordance or equivalence with regard to number, gender and person. Subject-verb agreement and noun/pronoun-antecedent agreement are two typical types. In contrast, agreement in Chinese language does not stand out. So the students commit lots of errors in this aspect. E.g.,

She is excited by the idea of online learning but he consider(s) it meaningless and useless. (Sentence 2)

Scientific research is an important means of knowing the world and at the same time serves as the foundations of technological progress. (Sentence 19)

c. Word order

The commonly accepted word order of Chinese indicative sentence is: Time adverb--space adverb--adverb modifying the main verb--verb; while the word order of that of English is: verb--adverb that modifying the verb--space adverb--time adverb. Moreover, in the case of an attributive clause modifying a noun, the arrangement of the Chinese sentence is: attributive clause--noun, while the English sentence is: noun--attributive clause. In English, there's frequently a long attributive clause after a noun, but it's not the case in Chinese. In C-E translation, the attributive clause is usually translated into an independent clause, or an attributive component before the noun. In addition, the preposition that refers to place is usually placed after the noun in Chinese, while in English it is just the opposite. Secondly, the generative methods are different between Chinese and English interrogative sentence. The word order of Chinese interrogative sentence is the same as the indicative ones, the only difference is that there is an interrogative word such as “吗”, “呢”, etc., at the end of the sentence. While in English interrogative sentences the subject and predicative verb is in an inverted order, the interrogative words, such as "what", "why", "where" are at the beginning of the sentence. However, the Chinese interrogative word only has to substitute the noun in the sentence.

For Sentence 1, “对于网络课程, 学生不仅可以选择何时何地学习, 在回答问题之前他们还可以有时间思考答 案”, many students translate it according to the word order of Chinese sentence, they translate the adverbial “对于网络 课程" into a short clause at the beginning of the whole sentence and the following word order is also not standard in English. E.g.,

(1)As for online course, not only can students choose when and where to study, but they also can have time to think out the answer before answering questions.

(2) About online course, not only students can choose when and where to study, but also they can think out answers before they answer the questions.

d. Relative clause

As we know English is compact while Chinese is diffusive, when we do C-E translation, we must pay attention to this difference. In English, the complex sentence usually has some conjunctions and the compound sentence usually has a relative pronoun. And for the compound relative sentence in English, there's usually a domain noun and a clause modifying the noun, so grammatically there's also a relative pronoun, and sometimes there's also a preposition before the relative pronoun according to the semantic meaning. One important difference between the domain noun in the main clause and the pronoun in the relative clause is that they may take different grammatical roles. This is different from Chinese sentence, which usually put the modifying clause before the noun, or just put another small clause after the noun. There is no relative pronoun. For example, in Chinese, we say, “刚才摔倒的那个女孩是我的妹妹”, but in English we say “The girl who has fallen down just now is my sister”. As for Sentence 3, “与以英语为母语的人交谈是 
非常有益的体验, 从中我们能学到许多东西”, many students make some errors in the attributive clause. E.g.,

(1) Communicating with the people whose first language is English is a rewarding experience, we can learn a lot from it.

(2) It's a rewarding experience to communicate with those whose mother tongue is English, and we can learn more from this.

e. Negation

In some languages, negators may either precede a verb phrase, or follow a verb phrase, we can call it preverb or postverb negation (Odlin, 2001). We can see that Chinese is a preverb language, we often use the negators “不”, “不是”, “并非” before the main verb. However, English is much more complex, aside from independent words, such as "no", "not" and "none", prefixes and suffixes may also serve as negators, as in "uninterested and thoughtless", etc. Moreover, English has many words which have negative meanings, such as, "little, few, seldom, hardly, scarcely, barely", "fail, lack, beyond, deny, refuse, reject", etc. So strictly speaking, English verb-phrase negators are often neither preverb nor postverb. When Chinese students come across the negation in C-E translation, they usually just put the negator "no" or "not" before the main verb. As for Sentences 2 and 5, the following are two versions of the students:

(1) She is excited by the idea of online learning, while he thinks it's no meaning and no use.

(2) In the short time of 15 years, China has changed into a place not recognize.

The reference translations are:

"She is excited by the idea of online learning while he considers it meaningless and useless."

"In the short space of fifteen years, China has changed beyond the recognition."

f. Dangling modifiers

Dangling modifiers is a kind of ungrammatical structure, such as, the phrases functioning as adjectives or adverbs are put at the illogical places. Dangling modifiers in the works of Chinese translators frequently appear in structures such as participles, gerunds, infinitives, prepositional phrases and adjectives and so on.

Some students translate Sentence 7, “我跑下了楼的时候, 听到钟敲了12下”, into, “While running down the stairs, the clock struck twelve."

The dangling participle in this sentence is "while running down the stairs" which needs to be closely linked to the subject "I". There is a difference between English and Chinese in participle. In Chinese, there is no participle, so the students made a Chinglish problem of dangling participle. While the standard version is, "While running down the stairs, I heard the clock strike twelve".

g. "It" plague

The native speakers of English often choose the pronoun "it" to be the subject or the object of the sentence in form. However, in Chinese, the subject is usually implied in the sentence. Some Chinese translators usually ignore this difference between these two languages.

In Sentence 8, “冷静耐心地处理这个微妙问题是明智的”, the subject is too long and too abstract to put at the top of the sentence. In English, it is an idiomatic way to put a pronoun "it" as the formal subject at the beginning of the sentence. However, in Chinese, we need not pay attention to that. There's no wonder some students translate it into: "To handle this delicate problem with calmness and patience would be wise." While the standard translation is, "It would be wise to handle this delicate problem with calmness and patience."

h. Missing subject

The first Chinese typical sentence is a theme-rheme sentence compared with English subject-predicate sentence. Theme invariably occurs first, and the rheme is a clause which follows the theme and says something about it. While it is widely accepted that English sentence is a language unit containing subject and predicate. This kind of structure in English is strictly obeyed and a predicative verb is the focus of each sentence. A theme in Chinese starts at the beginning of a sentence, but it can be or cannot be the subject in English sentence.

Just as Sentence 9, “明天下午两点在学校礼堂开教学研究会” Many students translated it into,

At 2:00 p.m. tomorrow in the school hall will hold a teaching symposium.

This version regards the theme in the Chinese sentence as the subject in the English sentence. While judging by the English grammar, this version is ungrammatical and lack of the subject. The student's ignoring of the difference between the two languages led to word to word translation. However, the reference version is, "A teaching symposium will be held in the school hall at 2:00 p.m. tomorrow".

4. Other transferred errors

a. Avoidance of passive voice

A great difference between Chinese and English is the frequent use of passive voice in English. As we know that in Chinese, the verb itself doesn't have the distinction between active and passive. Moreover, we usually tend to use the active form to mean a passive meaning. E.g. the sentence “鸟吃了” may have two meanings. One is "the bird has eaten (it)" and the other is "the bird has been eaten". The frequency of passive voice in Chinese is much smaller than that in English. Due to this fact, the students are unaware of the use of passive voice in some sentences. As for sentence No. 25 and 28, many students haven't used the passive voice. Those who have used also made some mistakes. E.g.,

Over the past ten years, the graduate education in China has made a great progress with common efforts. 
You should pay right after the goods are arrived.

The reference version is as follows:

Over the past ten years, with joint efforts a big progress has been made in graduate education in China.

You should make the payment right after the goods are delivered.

b. Avoidance of use the complex sentence

The avoidance of the complex sentence, especially the noun clauses, is also obvious in the students' versions. E.g.,

We will deal with the working of computer in details next period. (Sentence 22)

When we start doesn't matter. Being well-prepared is the most important thing. (Sentence 30)

The reference versions are:

How a computer works will be explained in detail at the next lecture.

When we start doesn't matter. The most important thing is that we should make good preparations for it.

\section{A Remarkable Finding}

On the back of the translation test paper, every student has been asked to write down their English scores in the College Entrance Examination (CEE). There's a remarkable finding during the analysis of the samples. That is, the students who have achieved high scores in the CEE have made fewer transferred errors than those who have got low scores. The total transferred errors and their scores can be seen in the following table. (Table 3-2)

TABLE 3-2

A CONTRAST BETWEEN STUDENTS' TRANSFERRED ERRORS AND CEE SCORES

\begin{tabular}{|l|l|l|}
\hline Student's number & numbers of transferred errors & scores in the CEE \\
\hline S No. 1 & 13 & 67 \\
\hline S No. 2 & 9 & 78 \\
\hline S No. 3 & 7 & 79 \\
\hline S No. 4 & 10 & 80 \\
\hline S No. 5 & 8 & 83 \\
\hline S No. 6 & 7 & 85 \\
\hline S No. 7 & 9 & 87 \\
\hline S No. 8 & 10 & 89 \\
\hline S No. 9 & 8 & 93 \\
\hline S No. 10 & 9 & 93 \\
\hline S No. 11 & 10 & 94 \\
\hline S No. 12 & 8 & 96 \\
\hline S No. 13 & 8 & 98 \\
\hline S No. 14 & 7 & 98 \\
\hline S No. 15 & 11 & 99 \\
\hline S No. 16 & 9 & 100 \\
\hline S No. 17 & 6 & 102 \\
\hline S No. 18 & 9 & 105 \\
\hline S No. 19 & 11 & 106 \\
\hline S No. 20 & 9 & 107 \\
\hline S No. 21 & 6 & 110 \\
\hline S No. 22 & 7 & 115 \\
\hline S No. 23 & 7 & 117 \\
\hline S No. 24 & 5 & 119 \\
\hline S No. 25 & 8 & 120 \\
\hline S No. 26 & 5 & 121 \\
\hline S No. 27 & 3 & 123 \\
\hline S No. 28 & 4 & 123 \\
\hline S No. 29 & 3 & 131 \\
\hline S No. 30 & 2 & 143 \\
\hline & & \\
\hline & & \\
\hline
\end{tabular}

This phenomenon has also been proved in Taylor's research (1975). He has done a research on English grammatical errors committed by Spanish students, who are in different English levels. He came to the conclusion that the lower-level students were greatly influenced by L1, while the higher-level students tend to made less such errors.

The data have been put into SPSS 16.0, and the correlations can be seen in the following table. (Table 3-3) 
TABLE 3-3

CORRELATIONS

\begin{tabular}{|l|l|l|l|}
\hline \multicolumn{2}{|l|}{ Correlations } & No. of T- e & S(s) in CEE \\
\hline \multirow{2}{*}{$\begin{array}{l}\text { No. of } \\
\text { T-e }\end{array}$} & Pearson Correlation & 1 & $-.755^{* *}$ \\
\cline { 2 - 4 } & Sig. (2-tailed) & & .000 \\
\cline { 2 - 4 } & $\mathrm{N}$ & 30 & 30 \\
\hline \multirow{2}{*}{$\begin{array}{l}\text { S(s) in } \\
\text { CEE }\end{array}$} & Pearson Correlation & $-.755^{* *}$ & 1 \\
\cline { 2 - 4 } & Sig. (2-tailed) & .000 & 30 \\
\cline { 2 - 4 } & $\mathrm{N}$ & 30 & \\
\hline $\begin{array}{l}\text { Correlation is significant at the 0.01 level (2-tailed). } \\
\text { In this table, No. of T-e refers to the number of transferred errors, and S(s) in CEE refers to the English scores in } \\
\text { College Entrance Examination. }\end{array}$ \\
\hline
\end{tabular}

We can see these two components, the number of transferred errors and the scores in College Entrance Examination is highly negative correlated, and the Pearson Correlation proficiency is -.755*.

\section{CONCLUSIONS AND IMPLICATIONS}

\section{A. Causes of the Transferred Errors}

1. The different thought patterns

Since language influences the way people perceive, organize and communicate, speakers of different languages have different ways of thinking. So the negative transfer of linguistic knowledge on the surface is the negative transfer of thought patterns in deep cognitive processes. The way people think is language-specific and the manifestation of their thought patterns. The thought patterns in a language, which are the ways we interpret the experience, are commonly accepted in this particular speech community by its people. So, different speech community embodies a distinct habitual mode of thought. Brought up in China, Chinese students are used to Chinese thinking patterns. Negative transfer of syntactic knowledge is in fact that of thought patterns. Then the negative transfer of Chinese thought patterns on students' C-E translation is just a typical example.

2. Lack of comprehensible input

According to Krashen (1982), a second language learner improves and progresses along the "natural order" when he or she receives second language "input" that is one step beyond his or her current stage of linguistic competence. That is called "The Input Hypothesis". That is a language acquirer who is at "level i" must receive comprehensible input that is at "level $\mathrm{i}+1$ ". So input is very important for the acquisition or learning of a foreign language. For example, if a student has never learned a structure, it is difficult for him to produce it. English is learned as a foreign language in China, so students, esp. the non-English majors, have few opportunities to acquire the language knowledge as is done in the acquisition of mother tongue. In most cases, students are consciously learning the language rather than acquiring the knowledge, in Krashen's words. Even if there is input, it might not become intake and be incorporated into the learner's linguistic system. As a result, students often suffer from the limited linguistic repertoire of English, and have to resort to their mother tongue when necessary.

3. Lack of comparison and contrast between Chinese and English

When students enter the college, passing CET4\&6 becomes their goal in college English learning. In order to pass the exams, teachers ask students to do lots of test papers, which occupies much time in English course. In the practice of sentence translation, the teachers usually just give students the equivalent answers, ignoring the difference between Chinese and English and lacking an awareness of cross-linguistic influence. They don't notice they should compare and contrast the different syntactic structures of Chinese and English.

\section{B. Implications for Teaching}

According to the results of experimental research and the causes to the transferred errors, some measures should been taken in future teaching.

1. Increasing comprehensive input and output

Comprehensive input and output should be increased in future English teaching and learning. E.g., students are to be asked to read all kinds of English newspapers and magazines. They also have to recite parts of the text and do some translation practices.

Swain (1985) claims comprehensible output is also indispensable to SLA. Translation is not only a basic need for communication between two different countries, but also a means to review and reinforce the linguistic knowledge that has just been learned, through which language learners can also check the deficiencies of their knowledge. So at the end of each class, the students should be assigned with some homework, such as, some sentence translation, the detailed understanding of the text, and sometimes a composition.

2. Increasing comparison and contrast between Chinese and English 
Due to the last item in the questionnaire, we can see few teachers have done well in this aspect. So it should be reinforced. The contrastive fields include phonology, lexicology, syntax, context and culture.

In actual classroom teaching, the teacher have to give abundant practice on the difference between two languages through imitation and reinforcement, in order to help students overcome the interference of their mother tongue and form new habits in the target language learning. E.g., every week the assignments of C-E sentence translations should be asked to hand in. At the beginning of the next week, the answers and analysis are given to the students. Sometimes, before giving the answer, the students can be asked to check their versions by themselves. Ideally, as only the learners are actually capable of making changes in their developing inter-language systems, the best form of correction a teacher can do is to offer the learners the opportunity to try to self correct. By repairing their translation breakdowns, the correct form will be internalized. In addition, for the intermediate or advanced learners, most of the linguistic errors can be corrected by themselves. Furthermore, English learners can gain more confidence in their language capacity if they have time to put their own errors correct. But in most cases students couldn't detect the errors that they have made. At this time the teacher can ask them to discuss with their classmates. After discussion, the answer will be given to them.

Moreover, it's also necessary for the teacher to compare the different cultures between the east and west. Language is influenced and shaped by culture. Every nation has different religious belief and different thinking way. Therefore, teachers need to find some methods to help the students notice the different thought patterns and tend to use English in a standard way.

\section{APPENDIX}

1. 对于网络课程, 学生不仅可以选择何时何地学习, 在回答问题之前他们还可以有时间思考答案。

2. 网上学习的想法使她非常兴奋, 而他认为网上学习毫无意义和用处。

3. 与以英语为母语的人交谈是非常有益的体验, 从中我们能学到许多东西。

4. 如今, 越来越多的人可以利用互联网查找他们需要的信息。

5. 在短短的十五年期间中国变得认不出来了。

6. 既然我们已经学完这门课程, 就应该多做些复习。

7. 我跑下了楼的时候, 听到钟敲了 12 下。

8. 冷静耐心地处理这个微妙问题是明智的。

9. 明天下午两点在学校礼堂开教学研究会。

10. 他能不能来, 还说不准。

11. 他的误解和解释, 雯雯倒喜欢, 这使她放心了一点。

12. 对于这次大会的精神, 对大会做出的各项决定，（我们）必须坚决贯彻执行。

13. 文艺是从属于政治的，但又反过来给予伟大的影响于政治。

14. 我觉得清扫车真残酷, 它把美丽的落叶视同垃圾, 有点不尽人情。

15. 我认为这是一个遗憾, 你没有更努力一些。

16. 每天做同样的事情, 他觉得这难以忍受。

17. 一片阴影掠过我的眼前, 记忆把我拉回到几十年前的一个黄昏。

18. 夏天给人们种种磨难与考验, 训练人的耐性、智慧跟机敏。

19. 科学研究是人类认识世界的重要途径, 也是技术进步的源泉。

20. 谦虚使人进步, 骄傲使人落后。

21. 对任何事情来说, 有准备都比没有准备好。

22. 计算机是如何工作的将在下一次课上做详细说明。

23. 有些人以为男孩子比女孩子聪明。然而, 事实末必如此。

24. 即使我们失败一百次, 天也不会塌下来。只要我们不失去信心，我们终将成功。

25. 过去的 10 年中, 经过共同努力, 在我国的研究生教育方面取得了很大的进步。

26. 老人读完信后失望之极, 竟用颤抖的手指把它撕得粉碎。

27. 我提议咱们会后马上去办公室找史密斯教授, 邀请他参加我们的英语晚会。

28. 你们应该在货物运到后立即付款。

29. 采用这个办法, 我们提高了学习英语的效率。

30. 我们何时开工并无关系。最重要的是我们必须做好准备。

The reference translations in English are as follows:

1) Not only can students choose when and where to learn for an online course, but they can also take time to think through answers before making a reply.

2) She is excited by the idea of online learning while he considers it meaningless and useless.

3) Communicating with native English speakers is a very rewarding experience from which we can learn a lot.

4) Today, more and more people have access to the Internet through which they look for the information they need.

5) In the short space of fifteen years, China has changed beyond the recognition. 
6) Now that we have finished the course, we shall start doing more revision work.

7) While running down the stairs, I heard the clock strike twelve.

8) It would be wise to handle this delicate problem with calmness and patience.

9) A teaching symposium will be held in the school hall at 2:00 p.m. tomorrow.

10) It is uncertain whether he could come.

11) Wenwen liked his misunderstanding of her refusal, and this made her relax a little.

12) We must firmly implement the guidelines and decisions adopted by this meeting.

13) Literature and art are subordinate to politics, but in their turn exert a great influence on politics.

14) I feel that the sweeping cars are too ruthless; they regard the fallen leaves as rubbish, somewhat inhumane.

15) I think it a pity that you didn't try harder.

16) a. To do the same thing every day he finds it unbearable.

b. He finds it unbearable to do the same thing every day.

c. He finds to do the same thing every day unbearable.

17) A shadow sweeps across my eyes and my memory draws me back to a dusk over ten years ago.

18) Summer gives man various kinds of tests, training their patience, wisdom and alertness.

19) Scientific research is an important means of understanding the world and at the same time serves as the foundation of technological progress.

20) Modesty makes people make progress, while (and) pride makes people lose behind.

21) It's better to be prepared than unprepared for everything.

22) How a computer works will be explained in detail at the next lecture.

23) Some people think that boys are cleverer than girls. This is not necessarily the case, however.

24) The world won't end even if we fail a hundred times. As long as we don't lose heart, we'll succeed in the end.

25) Over the past ten years, with joint efforts a big progress has been made in graduate education in China.

26) After reading the letter the old man was so disappointed that he tore it into little bits with trembling fingers.

27) I propose that we go to find Prof. Smith in his office right after the meeting and invite him to our English evening.

28) You should make the payment right after the goods are delivered.

29) Adopting this method, we have improved our efficiency in English learning.

30) When we start doesn't matter. The most important thing is that we should make good preparations for it.

\section{REFERENCES}

[1] Corder, S. P. (1971). Introducing Applied Linguistics. New York: Penguin Books.

[2] Ellis, R. (1994). The Study of Second Language Acquisition. Oxford: Oxford University Press.

[3] James, C. (1980). Contrastive Analysis. London: Longman.

[4] James, C. (2001). Errors in Language Learning and Use: Exploring Error Analysis. Beijing: Foreign Language Teaching and Research Press.

[5] Karashen, S. (1982). Principles and Practices of Second Language Acquisition. Oxford: Pergamon Press.

[6] Lado, R. (1957). Linguistics across Cultures. Annarbor: University Of Michigan Press

[7] Lian Shuneng. (2010). Contrastive Studies of English and Chinese. Beijing: Higher Education Press.

[8] Odlin, T. (2001). Language Transfer: Cross-linguistic influence in language learning. Shanghai: Shanghai Foreign Language Education Press.

[9] Richards, J. (1974). Error Analysis: Perspectives on Second Language Acquisition. London: Longman.

[10] Swain, M. (1985) Communicative competence: Some roles of comprehensible input and comprehensible output in its development. In Gass, S. and Madden, C. (Eds.), Input in Second Language Acquisition, pp. 235-256. New York: Newbury House.

[11] Taylor, B. P. (1975). Adult language learning strategies and their pedagogical implications. TESOL Qarterly 9, 391-99.

[12] Xiao Liming. (2002). English-Chinese Comparative Study and Translation. Shanghai: Shanhai Foreign Language Education Press.

[13] Yu Liming. (2004). Language Transfer and Second Language Acquisition. Shanghai: Shanghai Foreign Language Education Press.

[14] Wilss, W. (1996). Knowledge and Skills in Translator Behavior, Amsterdam/Philadelphia, John Benjamins.

Hui Ni was born in Heze, Shandong, China in 1982. She received her M.A. degree in (English) pedagogy from Bohai University, China in 2009.

She is currently an assistant in the School of foreign languages, Heze University, Heze, China. Her research interests include contrastive teaching and literary criticism. She has published many research papers in domestic magazines. E.g. A Contrastive Study on Images of Woman between Chinese and Western Traditional Cultures (Qufu, Shandong: Modern Chinese, 2011). 